\title{
Study on influencing factors of different producer services in Shandong and Guangdong
}

\author{
Yang Xiao ${ }^{1}$ \\ ${ }^{1}$ South China University of technology, Guangzhou,China
}

Keywords: Producer services, Vector autoregressive model, Research on the differences in influencing factors

\begin{abstract}
In his paper,using time series data of Shandong and Guangdong provinces in 1984-2015,Bulding the vector autoregression models, researching a lot of factors play different role in the development of producer services,such as industrialization degree. Changes in the development of industry, urbanization level, opening degree, and the size of Government. Studies have found that among the affecting factors, industrialization degree is the most significant effect for the development of producer services in Guangdong Province, followed by the size of the Government and opening degree, those have a positive effect on producer services.Influencing factors of development of producer services in Shandong province, followed by urbanization level, opening degree and the size of Government. Urbanization development of producer services is the most significant effects in Shandong, but level of industrialization is the most significant effects in Guangdong, the two provinces are experiencing different developmental stage, constantly improve the level of urbanization in Shandong province, is to give good opportunities to the development of producer services and industrial progress and deepen the process of industrial reform of Guangdong Province, can promote the development of producer services in Guangdong.
\end{abstract}

\section{山东、广东生产性服务业的影响因素差异研究 \\ 杨霄 1 \\ 1华南理工大学经济与贸易学院, 广州, 广东, 中国}

关键词: 生产性服务业、向量自回归模型、影响因素差异研究

中文摘要. 本文主要采用1984-2015年山东和广东两省的时间序列数据, 建立向量自回归模型, 研究工业化程度、工业发展转变方式、城镇化水平、对外开放程度、政府规模等因素在两省 生产性服务业发展过程中作用的不同。研究发现, 影响广东省生产性服务业发展的因素中, 工业化水平对服务业的影响最为显著, 其次为政府规模和对外开放程度, 均是对生产性服务 业具有正向拉动作用。影响山东省生产性服务业发展的因素中，依次为城镇化程度、对外开 放程度和政府规模。可见城镇化水平对山东的生产性服务业发展影响最为显著, 而广东则是 工业化水平，说明两省正经历着不同的阶段，山东省城镇化水平在不断完善，正给予生产性 服务业的发展以良好的机会, 而广东省工业化的进步及深化工业化改革进程, 可以推动广东 生产性服务业的发展。

\section{1. 研究意义}

生产性服务业是伴随着工业发展与分工深化而产生的新型服务产业, 发展生产性服务业 对于降低社会成本、主导全球生产网络和产品价值链, 提高产业发展素质和资源配置效率, 
具有重要的推动作用。随着工业化进程的深入和城镇化步伐的加快, 生产性服务业作为要素 投入到生产中, 在企业生产中均扮演者越来越重要的角色, 本文在前人研究的基础上, 延续 生产性服务业的研究工作。山东和广东作为经济实力相当的大省, 在经济总量上前三, 关于 其自身生产性服务业受各省自身自然因素或政府因素等的影响可能会存在差异, 本文立足通 过合适的理论研究方法发现影响两省生产性服务业差异的因素, 即这些因素对两省生产性服 务业发展所造成的不同影响，以便为省域发展提供合适的政策建议。

\section{2. 生产性服务业内涵及分类}

关于生产性服务业西方国家对此研究较早, 生产性服务业的概念最早由美国经济学家 H. Greenfield (1966) 提出, 认为生产性服务业是企业、非营利组织合政府主要向生产者而不 是最终消费者提供服务产品和劳动, 在理论内涵上是指市场化的中间投入服务, 即可用于商 品和服务的进一步生产的非最终消费服务。我国学者李江帆 (1986)认为, 广义生产服务指在 三次产业生产实物产品和服务产品过程中被作为生产要素投入的服务产品, 亦可称为 “服务 形式的生产资料”。本文认为生产性服务又称生产者服务, 是指那些主要为满足中间需求, 作为服务形式的生产资料，向外部企业和其他组织的生产活动提供中间投入服务的行业。

2015年国家统计局根据《国务院关于加快发展生产性服务业促进产业结构调整升级的指 导意见》和《国务院关于印发服务业发展 “十二五” 规划的通知》的要求, 制定了生产性服 务业分类。本文在此基础上又参考《国民经济行业分类》 (GB/T 4754-2011) 中分类的行业 数据的可获得性, 及前人对生产性服务业的研究结果, 将生产性服务业的分类制定为包含以 下行业：交通运输、仓储和邮政业, 信息传输、软件和信息技术服务业, 批发和零售业, 金 融业, 租赁和商务服务业, 科学研究和技术服务业。

\section{3. 因素及数据的选取}

关于生产性服务业的影响因素, 国内外学者主要从定性和定量两个角度, 对其影响因素 进行分析。其中, 朱胜勇（2009）基于0ECD国家生产性服务业的分析研究了发达国家生产性 服务业发展的影响因素, 认为制造业和服务业的中间需求、信息技术水平、市场环境变迁对 生产性服务业的发展具有较强的促进作用。孙青芬（2012）考察的影响因素为制造业规模、 固定资产投资、就业水平、区域经济水平和城市化水平。刘晶（2011）实证分析工业化水平、 市场发育程度、城市化水平和信息化水平等因素对生产性服务业发展的影响。

工业化程度-Ind, 采用工业生产增加值与GDP的比值表示。生产性服务业的发展离不开工 业尤其是制造业的发展。制造业的发展是生产性服务业需求的基础, 并为生产性服务业的发 展提供条件, 基于工业化程度对生产性服务业的影响及山东和广东在工业化进程中的差异提 出此影响因素; 对外开放程度--0pen, 采用进出口贸易总额与GDP的比率表示。对外开放程度 直接影响地区经济输入与输出, 因此对于生产性服务业的输入与输出也带来一定得影响。基 于山东半岛环抱渤海湾, 濒临日韩, 广东濒临香港, 是改革开放的前沿地带, 对外开放程度 上存在一定差异, 故本文选此为一个影响因素进行分析; 工业发展方式转变的程度--pro, 采 用工业增加值与工业总产值的比率表示。比率称为工业增加值率, 反映降低中间消耗的经济 效益, 也是工业发展方式转变的表现指标, 基于山东和广东工业发展方式转变的程度的不同, 在降低工业企业生产过程中中间消耗的经济效益方面的差异, 特选此因素作为研究对象之一; 城镇化程度一 ubran, 采用第二三产业增加值占地区生产总值的比重来衡量。第二三产业主要 集中在城市与城镇, 二三产业发展越迅猛, 表明城镇化越明显, 基于两省城镇化的差异特选 此因素; 政府规模程度--Gov, 采用政府消费占最终消费的比重来表示。一般来说, 较大的政 府规模具有较强的行政干预能力。对于生产性服务业, 尤其是金融保险、科学研究、信息技 术等涉及国民经济命脉的生产性服务业, 政府的干预较多, 政府管制也更加严厉。因此, 相 对于制造业, 政府的行政干预会阻碍生产性服务业的发展。此外, 一些政府行为本身可能会 
对生产性服务业的发展产生替代效应, 山东和广东相比, 山东作为孔孟之乡, 深受孔孟文化 熏陶, 而广东作为改革开放的前沿地带, 两省在政府对经济的干预程度上可能存在不同, 因 此本文将政府干预程度这一因素做为对生产性服务业发展得一个影响因素进行分析; 生产性 服务业发展水平一Pros，采用生产性服务业增加值占GDP的比重来代表。采用比率指标作为被 解释变量, 可防止变量数据之间绝对量过度差异对模型构建造成影响。

本文主要选取工业化程度、对外开放程度、工业发展方式转变程度、城镇化程度、政府 规模等几个因素。从城市发展阶段、行业发展周期、市场化程度等几个方面, 对生产性服务 业的发展进行研究, 以企通过上述因素的分析, 比较山东省和广东省在生产性服务业发展过 程中存在的差异，为省域生产性服务业的发展提供参考。

\section{4. 理论模型的设定}

\section{1 向量自回归模型概念定义}

向量自回归是指系统内每个方程有相同的右侧变量, 而这些右侧变量包括所有内生变量 的滞后值。当每个变量都对预测其他变量起作用时, 这组变量适合用VAR模型表示。

VAR的数学形式是 $y_{t}=A_{1} y_{t-1}+\cdots+A_{N} y_{t-N}+B x_{t}+\varepsilon_{t}$ 这里 $y_{t}$ 是一个内生变量向量, $x_{t}$ 是外生变量向量, $A_{1}, \cdots \cdots A_{N}$ 和 $\mathrm{B}$ 是待估的系数矩阵, 而 $\varepsilon_{t}$ 则 是误差向量。这些误差向量之间相关，但是与它们自己的滞后值不相关，与 $y_{t-1}, \cdots \cdots, y_{t-N}$ 和 $x_{t}$ 也不相关。

\section{2 选择用向量自回归模型进行影响因素分析的文献资料}

简晓须，周敏（2013）以江苏省为例，以向量自回归（VAR）模型为基础，运用协整检验、 格兰杰因果检验、方差分解和脉冲响应分析等技术, 综合考察了技术创新、生产性服务业、 产业集群、制造业规模等因素对江苏制造业价值链攀升的影响。曹孜, 鲁芳 (2012) 以湖南、 广东为例, 通过建立自回归模型和对因素之间协调发展度的测量, 研究了当前产业区域转移 背景下, 影响湖南、广东生产性服务业发展的具体因素———城镇化水平、工业水平、开放 度、市场化水平。万千欢, 千庆兰 (2014) 基于2001-2011年广州市生产性服务业的相关数 据, 运用灰色关联分析对影响广州市生产性服务业的主导因素进行了识别, 在此基础上运用 协整分析及脉冲响应分析法对主导因素与生产性服务业之间的关系进行了实证分析。

本文基于时间序列数据, 运用1984-2015年数据, 样本量符合模型要求, 根据数据的分析 与检验结果, 先分别对两省数据对数化处理后, $\mathrm{ADF}$ 检验原序列不平稳, 但一阶差分平稳, 在 同阶单整的情况下进行Johanson协整检验, 结果两省均存在协整关系, 因此本文进一步选择 用向量自回归模型进行模型构建。

\section{5. 模型的选择与建立}

\section{1 平稳性检验}

本文主要采用ADF检验对序列的单位根进行检验, 分别将鲁粤两地对数化后的数据, 进行 $\mathrm{ADF}$ 检验发现, 仅城镇化程度平稳, 其他为非平稳序列, 因而将所有序列进行一阶差分, 差分 后序列包括生产性服务业发展水平, 工业化程度、对外开放程度、专业化程度、政府干预程 度等所有指标序列均为平稳, 因而选取的数据均为同阶单整的, 故而要进行协整检验, 检验 是否存在协整关系, 及协整方程的平稳性。

\section{2 协整检验}

协整是指, 变量之间存在共同的随机性趋势。协整检验的目的是检验一组非平稳序列的 线性组合是否具有稳定的均衡关系, 避免该种类型伪回归的出现。同时, 在引入协整关系的 过程中, 可以通过调整排除单位根带来的随机性趋势, 建立误差修正模型。 
表1: 山东省序列Johanson检验结果表

\begin{tabular}{|c|c|c|c|c|c|c|c|c|c|}
\hline No. of $C E(s)$ & $\begin{array}{l}\text { Eigen } \\
\text { value }\end{array}$ & Statistic & $\begin{array}{l}\text { Critical } \\
\text { Value }\end{array}$ & Prob. ** & $\begin{array}{l}\text { No. of } \\
\text { CE(s) }\end{array}$ & $\begin{array}{l}\text { Eigen } \\
\text { value }\end{array}$ & Statistic & $\begin{array}{l}\text { Critical } \\
\text { Value }\end{array}$ & Prob.** \\
\hline None * & 0.68 & 100.20 & 95.75 & 0.0239 & & 0.70 & 125.45 & 95.75 & 0.0001 \\
\hline At most 1 & 0.63 & 65.67 & 69.82 & 0.1024 & & 0.58 & 81.58 & 69.82 & 0.0043 \\
\hline At most 2 & 0.46 & 35.81 & 47.86 & 0.4061 & & 0.49 & 50.02 & 47.86 & 0.0308 \\
\hline At most 3 & 0.32 & 17.53 & 29.80 & 0.6009 & & 0.34 & 25.83 & 29.80 & 0.1339 \\
\hline
\end{tabular}

Trace test indicates 3 cointegrating eqn(s) at the 0.05 level

* denotes rejection of the hypothesis at the 0.05 level

${ }^{* *}$ MacKinnon-Haug-Michelis (1999) p-values

由表1可知山东省序列协整检验结果，第一行Trace Statistic的值为100. 1963>95. 75, 即大于临界值, 且P值等于 0.023 , 小于 0.05 , 则表示在 $95 \%$ 置信水平上拒绝了原假设 (即拒绝 了不存在协整关系的假设）, 说明变量之间至少存在 1 个协整关系; 由表 2 可知广东省序列协 整检验结果，第一行Trace Statistic 的值为 $125.448>95.7536$, 即在95\%置信水平上拒绝了原 假设（即拒绝了不存在协整关系的假设）；第二行，81.58297>69.81889，即在95\%置信水平 上拒绝了原假设（最多存在 1 个协整关系），第三行 $50.02185>47.85613$, 即在 $95 \%$ 置信水平上 拒绝了原假设（最多存在 2 个协整关系），说明通过对广东省序列进行Johanson检验得到变量 之间存在 3 个协整关系。

表3: 山东省序列Johanson检验协整方程标准化的系数估计:

1 Cointegrating Equation(s):

Log likelihood

372.8403

\begin{tabular}{|c|c|c|c|c|c|}
\hline $\begin{array}{c}\text { APRODUCER_SERV_LN } \\
1.000000\end{array}$ & $\begin{array}{c}\text { GOVERNMENT_LN } \\
-0.059267 \\
(0.05948) \\
\end{array}$ & $\begin{array}{l}\text { INDUSTRAL_LN } \\
1.590821 \\
(0.13679) \\
\end{array}$ & $\begin{array}{c}\text { OPEN_LN } \\
-0.104099 \\
(0.04319) \\
\end{array}$ & $\begin{array}{c}\text { PROFESSIONAL_LN } \\
0.101111 \\
(0.05489) \\
\end{array}$ & $\begin{array}{c}\text { UBRAN2_LN } \\
-2.630451 \\
(0.13707) \\
\end{array}$ \\
\hline \multicolumn{6}{|c|}{ 表4: 广东省序列Johanson检验协整方程标准化的系数估计: } \\
\hline 1 Cointegrating Equation & & Log likelihood & 407.051 & & \\
\hline $\begin{array}{l}\text { Normalized cointegrati } \\
\text { APRODUCER_SERV }\end{array}$ & $\begin{array}{l}\text { Defficients (standa } \\
\text { OVERNMENT_GL }\end{array}$ & $\begin{array}{l}\text { ror in parenthe } \\
\text { NDUSTRAL_G }\end{array}$ & S) OPEN_C & & \\
\hline $\begin{array}{c}\text { D_LN } \\
1.000000\end{array}$ & $\begin{array}{c}\text { LN } \\
-0.661438 \\
(0.35794)\end{array}$ & $\begin{array}{c}\mathrm{LN} \\
-0.974927 \\
(1.02598)\end{array}$ & $\begin{array}{c}\bar{N} \\
-0.58314 \\
(0.16600\end{array}$ & $\begin{array}{c}\text { LN } \\
4.167310 \\
(0.86784)\end{array}$ & $\begin{array}{c}\mathrm{LN}^{-} \\
6.934471 \\
(2.31015)\end{array}$ \\
\hline
\end{tabular}

协整检验的结果在95\%置信水平上山东省至少有一个协整关系存在，广东省有三个协整关 系存在, 由上表 5 和表 6 可知一个协整关系的情况下标准化的系数估计值, 因此可分别根据第 一个协整方程各内生变量得到如式（1）、（2）所示的长期均衡关系:

Pros $=0.0593$ Gov-1.5908 Ind +0. 1041 Open-0.1011 pro+2. 6305 ubran

(1) 山东省

Pros $=0.6614$ Gov+0. 9749 Ind +0.5831 Open -4.1673 pro-6. 9345 ubran

(2) 广东省

其次，对协整关系进行验证。在确定了变量间的协整关系之后，有两种方法可验证协整 关系的正确性，一是单位根检验，对协整关系序列进行单位根（EG、AEG）检验，也可画vecm 时序图验证协整关系的正确性。二是AR根的图表验证, 本文采用第二种方法即AR检验, 关于 $A R$ 特征方程的特征根的倒数绝对值小于 1 , 即位于单位圆内, 则模型是稳定的, 否则模型不稳 定, 某些结果（如脉冲响应函数的标准误差）不是有效的。

图1: 山东省变量协整关系AR根的图表验证

广东省变量协整关系AR根的图表验证
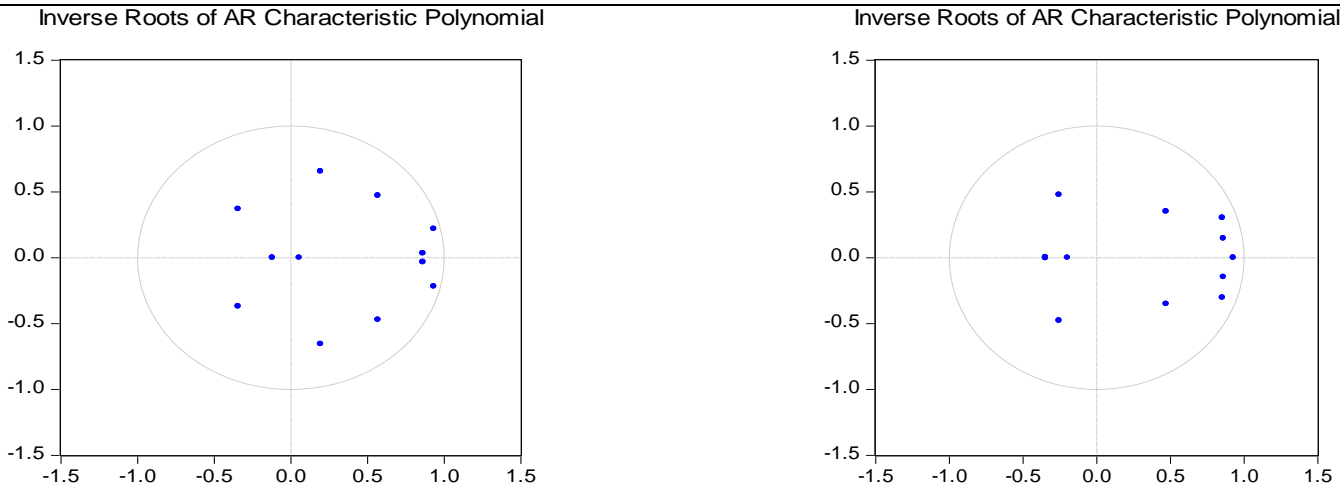
根据上图, 两省的序列数据通过了AR检验, 说明协整关系具有长期平稳性, 因此具有经 济意义，故而可继续建立模型。

\section{3 建立VAR模型}

根据LR、AIC、SC、HQ准则，本文确定最佳滞后阶数为1阶，将序列Ind、Gov、0pen、pro、 ubran的非限制性VAR模型进行标准化系数估计, 出于研究目的的需要, 本文只列出了以Pros 为被解释变量的估计结果。

表5: 自回归估计

\begin{tabular}{lccccccc}
\hline & ProsR(-1) & GovR(-1) & IndR(-1) & OpenR(-1) & proR(-1) & ubranR(-1) & \multicolumn{1}{c}{ C } \\
\hline Pros & 1.266321 & -0.117612 & 0.816388 & -0.034883 & -0.152971 & -1.092811 & 0.517081 \\
山东省 & $(0.22005)$ & $(0.04851)$ & $(0.32027)$ & $(0.04443)$ & $(0.06501)$ & $(0.52908)$ & $(0.59055)$ \\
Pros & {$[5.75464]$} & {$[-2.42441]$} & {$[2.54908]$} & {$[-0.78518]$} & {$[-2.35286]$} & {$[-2.06549]$} & {$[0.87559]$} \\
广东省 & 0.869914 & {$[7.08788]$} & 0.329988 & 0.009579 & -0.154372 & -0.382898 & -0.119577 \\
& $(0.12273)$ & 0.018350 & $(0.44225)$ & $(0.06602)$ & $(0.41414)$ & $(0.91166)$ & $(0.77543)$ \\
& {$[7.08788]$} & $(0.14657)$ & {$[0.74616]$} & {$[0.14510]$} & {$[-0.37275]$} & {$[-0.42000]$} & {$[-0.15421]$} \\
\hline
\end{tabular}

注: 圆括号中为估计系数的标准差, 方括号中为 $\mathrm{t}-$ 统计量

自回归模型拟合优度高, 山东序列模型调整的 $R^{2}=0.978$, 广东省序列模型拟合调整的 $\mathrm{R}^{2}=0.78$, 自变量对因变量的解释程度较高, 因此回归结果有较强的可信度。

\section{6. 根据实证结果进行分析}

\section{1 根据协整关系方程分析两省各因素对生产性服务业影响的差异}

由上式的 (1) 和 (2) 所示的长期均衡关系, 山东省的自变量系数从大到小依次是UBRAB2、 OPEN、GOV、PRO、IND。表明城镇化水平每提高 $1 \%$ ，生产性服务业提高 $2.63 \%$; 开放程度提高 $1 \%$ ，生产性服务业提高0.104\%，政府规模提高1\%，生产性服务业提高0.0593\%；工业发展方式 转变的程度提高 $1 \%$, 生产性服务业下降 $0.101 \%$ ，工业化程度提高 $1 \%$, 生产性服务业下降 $1.59 \%$ 。 城市化产生集聚效应, 吸引金融、物流运输、商务服务以城市为中心向周围产生辐射。由于 山东省内区域之间、城乡之间经济发展水平差异较大, 城市对生产性服务业的极化作用更为 明显。人口和产业的聚集会对配套的生产性服务业形成需求效应, 使生产性服务业和其它产 业以城市为载体, 借助集群优势互动升级。对外开放程度同理论假设一致, 对生产性服务业 产生正向拉动作用; 政府规模的实证结果显示, 政府规模越大、干预程度越高, 就越能促进 生产性服务业发展, 这与前面的理论假设刚好相反。一个可能的解释是, 政府规模与生产性 服务业发展的关系存在一个由正变负的过程，即存在门限效应，在生产性服务业发展初期， 政府干预能在一定程度上推动本地生产性服务业的发展, 但当生产性服务业发展到一定程度 时, 政府干预则会阻碍生产性服务业的发展。说明两省政府对生产性服务业的发展还没有越 过门限效应, 侧面反映两省生产性服务业的发展水平还比较低。工业发展方式的转变程度对 生产性服务业发展水平呈负相关, 与设想不一致, 工业的增加值率反映了投入产出效果, 数 值越高, 企业的附加值越高、盈利水平越高, 投入产出的效果越佳。可能是工业发展方式的 转变还处于较低的阶段, 对于生产性服务业的影响还处于负面影响的效果。

影响广东省生产性服务业发展得因素依次为IND、GOV、OPEN、PRO、UBRAB2，工业化水 平对服务业的影响最为显著, 其次为政府规模和对外开放程度, 均是对生产性服务业具有正 向拉动作用。工业以其开放性和高端化同服务业联系融合较好, 所以广东工业对服务业的影 响与山东省不同, 其有正向的推动作用。相对于其它几项影响因素, 城市化对生产性服务业 的影响为负。从原始数据可以观察到, 1985年后广东省城市化进程较为缓慢; 另外广东省有 大量外来无本地户籍者流入，没有计入城镇人口的范围，却发挥着城市产业工人的作用。

将两地协整方程的系数做比较，工业水平的系数正负相反，山东省为负，广东省为正。 工业水平的系数为负说明服务业和工业之间没有建立起良性互动关系, 具体表现在工业企业 大多在内部设置产品设计、技术研发、商务服务、售后服务等生产性服务业环节。由于企业 自身的业务范围和实力限制, 生产性服务达不到专业化、规模化, 所以对内限制产品科技含 
量和附加值的增加, 对外造成工业发展挤占生产性服务业独立发展的空间。说明山东省在服 务业和工业之间没有建立起良性互动关系, 应向广东省学习和借鉴。对外开放程度系数广东 省大于山东省, 广东省对生产性服务业的拉动作用要强于山东省, 广东临海的地理位置加上 改革开放以来作为经济特区, 招商引资使得中国香港、中国台湾及海外大量的制造企业投资 办厂, 拉动了对生产性服务业的需求。另外在国际服务贸易转移过程中, 众多跨国公司也因 为广东产业基础、市场制度、地理位置等方面的优势, 而将其视为理想的场所。所以, 虽然 山东半岛濒临日韩, 但在对外开放上应仍向广东省进行学习借鉴, 为生产性服务发展创造良 好条件。政府规模虽然存在门限效应, 但广东省政府规模影响因素对生产性服务业的正向拉 动效应要强于山东省, 可能是政府消费作为生产性服务业消费主力, 通过服务外包等形式对 生产性服务形成了更多的市场需求, 进而拉动生产性服务业的发展, 因此, 在门限效应的合 理范围内, 山东省可以适度增加政府的消费, 通过服务外包等形式推动地方生产性服务业的 发展。

\section{2 根据模型参数估计进行分析}

根据模型参数估计进行分析, (1)从服务业自相关上看, 山东省 -1 期系数为 1.266 , 大于广 东省的 -1 期系数 0.8699 , 可知山东省上一期生产性服务业的发展对本期生产性服务业产生非 常大的正向影响, 其生产性服务业存在一定的路径依赖性, 产业结构、增长方式受前一期发 展水平影响强, 发展的自我延续性较强; (2)政府规模一项山东省 -1 期系数为负值, 可知, 若 上一期政府规模扩大会对本期生产性服务业造成负面带动效果, 可能原因是政府的挤出效应, 广东省 -1 期的效果为正, 但不显著, 说明广东省上一期的政府规模对本期生产性服务业没有 产生太大拉动作用, 政府行为也没有对本期生产性服务业的发展形成挤出效应, 广东省政府 在参与市场经济的过程中表现要优于山东省。(3)工业化程度一项, 两省 -1 期系数均为正值, 山东省 -1 期系数为 0.8163 , 大于广东省 -1 期系数 0.3299 , 山东省上一期工业化的发展对本期 生产性服务业的正向拉动作用要大于广东省, 另外, 山东省的表现与协整关系中的负值相反, 说明山东省工业建设的加速对一年之后生产性服务业发展有积极影响, 广东省的表现与协整 关系中的正值表现一致, 说明广东省工业发展对生产性服务业的拉动作用至少保持了两期, 其影响具有持续性。(4)山东省 -1 期开放度系数为 -0.034 , 与协整关系中的正值表现相反, 说 明前期开放度能够有效推动下期生产性服务业的发展。广东省 -1 期开放度系数为 0.00957 , 与 协整关系中的数值均为正, 开放性的延伸作用效果更强。这同改革开放已经形成气候, 对外 型经济对生产性服务业有持续拉动作用有关。(5)工业的发展方式的转变程度一项两省均为负 值, 与协整关系方程中系数方向一致, 说明工业的发展方式的转变程度并不像理论想象的会 对生产性服务业的发展带来正向的带动作用, 可能是工业发展方式的转变体现的是工业企业 效率的提升, 工业发展质量的提升, 中间消耗的降低, 对于生产性服务业直接的带动效果不 明显。(6)城镇化一项山东省系数为 -1.0928 , 与协整关系方程中方向相反, 说明城镇化对于山 东省生产性服务业的发展效果较快, 本期对本期影响较大, 上一期对本期的影响不大。

\section{7. 政策建议}

山东省应积极推进城镇化建设、进一步巩固对外开放, 在门限效应的适度线以下适度加 强政府规模, 以促进山东省生产性服务业的发展。广东省应加强工业化程度, 积极推动工业 化改革, 进一步巩固对外开放程度, 适度加强政府规模, 以促进广东省生产性服务业的发展。

\section{1 立足产业比较优势, 积极推进山东省城镇化建设}

一是在农业方面, 进一步调整农业结构把满足城市多方面消费需求作为调整的切入点, 大力发展以生产肉、蛋、奶、果、菜、花及其深加工产品为主的城郊型农业和都市农业, 同 时切实加快观光旅游农业的发展, 使农村经济伴随着城镇化的步伐得到进一步优化和繁荣, 使农民群众实现增产增收, 为加快农村人口向城镇转移奠定更为坚实的基础; 二是在工业方 面, 要加快产业结构调整, 实施传统产业的升级改造和发展战略性新兴产业 “双轮驱动”, 
尤其是在海洋产业发展方面, 要借助山东半岛蓝色经济区建设的有利时机, 打造海洋产业发 展的新高地; 三是在服务业方面, 要将城镇服务业发展作为推进新型城镇化的重要任务, 增 强城镇发展的动力和活力。

\section{2 积极推动广东省工业化进程}

一是推动信息化带动工业化, 工业化促进信息化。以电子信息产业为先导的新兴产业群 不断发展壮大, 企业信息化水平迅速提高。二是推动产业空间布局调整优化, 实现集约发展。 依托中心城市和中心镇, 沿主要城镇发展轴, 大力推进高新技术产业开发区和工业园区建设。 三是加快欠发达地区工业化进程, 提高全省工业化水平。东西两翼和山区等欠发达地区要把 工业化摆在突出的位置抓紧抓好, 加强领导, 狠抓落实, 积极推进本地区工业化进程。要充 分利用自然资源、矿产资源、海洋资源、农产品等比较优势, 大力发展资源加工型产业、特 色产业和电力工业等。

\section{3 提高生产性服务业开放程度，建立同国际接轨、高效多元化的经营体系}

积极推进服务业国际外包、离岸贸易，使中资企业能够走出国门，依靠打造国际知名品 牌提高市场竞争力。依托本地大型跨国生产企业, 改变其生产性服务从母国进口的封闭式经 营策略，通过技术创新和优惠政策实现生产性服务本地化。鼓励国际FDI投资于国内生产性服 务业，重点在于使其参与垄断性的金融、运输、物流业国企的并购重组，以盘活国有资产， 提高其影响力和经营效益。

\section{4 积极推动生产性服务业市场化进度。}

广东省改革开放以来在开放程度、工业现代化等方面取得了较大进展。山东省生产性服 务业要想进一步繁荣起来, 就必须着力提升市场化水平, 加快同服务业的融合, 引进先进技 术, 促进服务外包和离岸贸易, 并通过改良政企关系、优化资源配置和健全制度法律, 推进 服务业市场化改革。

\section{References}

[1] Ma Jing Hong, Zhang xibao. Empirical research on the specialization of manufacturing in Bohai [j]. Economic research guide, 2012,04:153-156.

[2] Cao $\mathrm{Zi}$, Lu Fang, Peng Huaisheng. Industrial transfer analysis of the factors affecting the development of producer services in the context - in Hunan, Guangdong Province, as the example [j]. Scientific and technological progress and countermeasures, 2012,07:74-79.

[3] Zhang Yanqun. Global theory, method and application of vector autoregression model [j]. Quantitative technical and economic studies, 2012,04:136-149.

[4] An Husen, Zhang gu. Development gaps within China's developed provinces of the theoretical explanation and solutions - a case study of Shandong, Guangdong and Jiangsu [j]. Probe into modern economics, 2015,06:17-22.

[5] the bi Dou, Fang Yuanping, Bryson John, thanks man, Tang Yao. Development of producer services in China and its influencing factors--levels of temporal and spatial differences based on provincial spatial econometric analysis [j]. Economic geography, 2015,08:104-113.

[6] Li Xiaogang, Lu Pei. 11 city, Zhejiang Province, comparative analysis of the regional differences of producer services [j]. The SAR economy, 2009,07:46-47.

[7] Zhu Shengyong. The influencing factors of the development of producer services in developed countries--an analysis of producer services in OECD countries [j]. Urban problems, 2009,07:90-96.

[8] thousands of joyous, Qian Qing LAN, Chen Yingbiao. Study on influence factors of producer services, Guangzhou City, China [j]. Economic geography, 2014,01:89-93.

[9] Guo Lijuan. Analysis on the regional difference and influence factors of the development of producer services [d]. Zhejiang gongshang University, 2010. 
[10] Sun Qingfen. Development of producer services in China and its influencing factors [d]. dongbei University, 2012.

[11] dupeng. Comparative study on the regional difference of China's modern service industry and its [d]., Jilin University, 2013.

[12]Liu Chunbin, EAV. Study on the influencing factors of the development of producer services in China--based on the analysis of panel data and industry [j]. Journal of Shanxi finance and Economics University, 2013,04:30-37+48. 